Utah State University

DigitalCommons@USU

3-19-2019

\title{
Invasive Coqui Frogs Are Associated With Differences in Mongoose and Rat Abundances and Diets in Hawaii
}

\author{
Shane A. Hill \\ Utah State University \\ Karen H. Beard \\ Utah State University \\ Shane R. Siers \\ National Wildlife Research Center, Hawaii Field Station \\ Aaron B. Shiels \\ National Wildlife Research Center, Ft. Collins
}

Follow this and additional works at: https://digitalcommons.usu.edu/eco_pubs

Part of the Life Sciences Commons

\section{Recommended Citation}

Hill, S.A., Beard, K.H., Siers, S.R. et al. Biol Invasions (2019). https://doi.org/10.1007/s10530-019-01965-3

This Article is brought to you for free and open access by the Ecology Center at DigitalCommons@USU. It has been accepted for inclusion in Ecology Center Publications by an authorized administrator of DigitalCommons@USU.

For more information, please contact

digitalcommons@usu.edu.

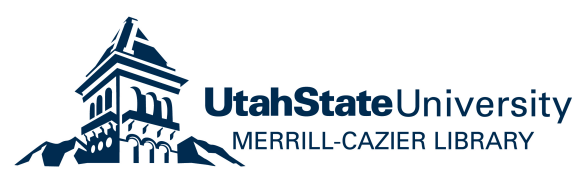


Click here to view linked References

1

2

3

4

1 Running head: Interactions among an invasive frog and invasive mammals

2

3 Invasive coqui frogs are associated with differences in mongoose and rat abundances and diets in Hawaii

5

1 Department of Wildland Resources and Ecology Center, Utah State University, Logan,

9 UT 84322-5230, U.S.A.

10

112 USDA APHIS, Wildlife Services, National Wildlife Research Center, Hawaii Field

12 Station, Hilo, Hawaii 96720, U.S.A.

13

143 USDA APHIS, Wildlife Services, National Wildlife Research Center, Ft. Collins, CO

15 80521, U.S.A.

16

17 * Email address: karen.beard@usu.edu; Orcid: 0000-0003-4997-2495; ph.: +1 435-797-8220

18

19 Keywords: Eleutherodactylus coqui; Herpestes auropunctatus; Island Rattus spp.; Nest

20 predation; Scavenger; Trophic interactions

21

22 Type of paper: Original Research 


\section{Abstract}

24 With the increasing rate of species being introduced to areas outside of their native 25 ranges, non-natives are likely to interact in ways that influence each other's populations. The 26 high densities of invasive coqui frogs (Eleutherodactylus coqui) in Hawaii have been 27 hypothesized to increase non-native mongoose (Herpestes auropunctatus) and rat (Rattus spp.) 28 abundances, and in turn increase bird nest depredation rates. We compared the relative 29 abundances of rats and mongooses and artificial bird nest predation rates at 12 sites that had plots 30 with similar habitat invaded and not invaded by coqui frogs across the island of Hawaii. We

31 interpret our results considering mongoose and rat stomach analyses and camera trap data 32 collected to monitor coqui scavengers. We found that coqui presence was associated with $30 \%$ 33 greater mongoose abundance and 17\% lower Pacific rat (Rattus exulans) abundance. Based on 34 our diet analyses and scavenging data, both mongooses and rats consume coquis, but mongooses 35 were the most important consumers of coquis, which may have contributed to their increase in 36 coqui plots. We speculate that coquis are competing with rats for invertebrate prey due to 37 reduced Pacific rat abundance and greater amounts of fruit in rat stomachs collected in coqui38 invaded compared to uninvaded plots. We did not observe any difference in nest predation rates 39 in coqui-invaded and uninvaded plots. Our results suggest that the coqui invasion may increase 40 or decrease non-native mammal populations, and non-native amphibians may serve as both novel 41 prey and competitors to non-native mammals. 
42 Introduction

43 A main negative effect of non-native fauna on islands is as novel predators (Davis 2003;

44 Sax et al. 2002), and the consequences are particularly noteworthy when these introduced

45 predators eliminate or greatly reduce native species (Atkinson 1985; Savidge 1987). However, as

46 invasive species become increasingly widespread and abundant, they are starting to interact with

47 one another in complex and difficult to predict ways (Simberloff and Von Holle 1999). Given the

48 growing number of non-natives and their potential for complex interactions, it is not surprising

49 that there is also growing evidence that non-native species can serve as important prey for non-

50 native predators (Abernethy et al. 2016; Beckmann and Shine 2011; Gangoso et al. 2006;

51 Rodriguez 2006). While these types of interactions might be most noteworthy if they negatively

52 affect native species, these effects can also occur among non-native species in completely novel

53 food webs. There is growing support for these types of complex interactions among non-natives,

54 sometimes termed invasional meltdowns (sensu Simberloff and Von Holle 1999), with examples

55 from yellow ant and scale insects on Christmas Island, and green crabs and clams in North

56 America (Grosholz 2005; O’Dowd et al. 2003; reviewed in O’Loughlin and Green 2017).

57 A region of the world that has experienced a large number of intentional and

58 unintentional invasions is the Hawaiian archipelago (Loope and Mueller-Dombois 1989;

59 Vitousek et al. 1987; Wilcove et al. 1998). Because there are no native ground-dwelling

60 mammals, reptiles, or amphibians, the ecological threat that non-natives pose is mostly limited to

61 native birds (Atkinson 1977; Hoshide et al. 1990; Reed et al. 2012), invertebrates (Choi and

62 Beard 2012; Hadfield et al. 1993), and plants (Shiels 2010; Sugihara 1997; Weller et al. 2018).

63 One such introduction of a non-native to Hawaii is that of the Puerto Rican coqui frog

64 (Eleutherodactylus coqui) (Kraus et al. 1999). The coqui has received a great deal of attention 
65 since it was introduced via the horticultural trade in the late 1980's (Kraus et al. 1999). The frog

66 is particularly widespread on the island of Hawaii, while the other Hawaiian Islands have had

67 more success in preventing its establishment and controlling populations (Beard et al. 2009).

68 Previous studies have found that coquis have both societal impacts, including economic and

69 quality of life impacts (Kaiser and Burnett 2006; Kalnicky et al. 2014; Kraus and Campbell

70 2002), and ecological impacts through their interactions with other species (Bernard and Mautz

71 2016; Choi and Beard 2012; Smith et al. 2018; Tuttle et al. 2009).

72 Although previous research has determined some ecological consequences of the coqui

73 invasion, questions remain regarding interactions between coquis and invasive small mammals.

74 The introduction of coquis to the island of Hawaii is recent relative to that of the mongooses

75 (Herpestes auropunctatus) and rats (Rattus spp.) (Baldwin et al. 1952; Doty 1945; Kraus et al.

76 1999), and, when coquis established, they became potential prey to these species. Further, if

77 coquis serve as novel prey to these species, it could change the roles that mongooses and rats

78 have within the Hawaiian food web. For example, coquis may increase rat and mongoose

79 abundances and exacerbate the predation effects of both mongooses and rats on native birds

80 (Kraus et al. 1999; VanderWerf 2001; Beard and Pitt 2006). Interactions observed in native

81 communities may also occur within this non-native dominated system, such as apparent

82 competition (sensu Holt 1977). For example, if the presence of coquis causes an increase in

83 mongooses, then there may be increased predation on rats by mongooses in coqui-infested areas,

84 eventually leading to a decrease in rats. Finally, coquis may compete directly with rats for prey

85 because both are nocturnal and insectivorous (Shiels et al. 2013; Wallis et al. 2016).

86 Our primary goal was to test the hypothesis proposed by Kraus et al. (1999) that coquis

87 may increase the abundances of mongooses and rats through direct predation and thereby 
88 increase bird nest predation. However, this hypothesis provides only a simple view of the

89 potential interactions among these species, especially between coquis and rats. Therefore, we

90 investigated likely alternative, but not mutually exclusive, hypotheses between coquis and rats,

91 such as apparent competition and resource competition. If coquis serve as important prey for

92 mongooses and rats, we predict that mongoose and rat abundance will be higher in areas with

93 coquis and we expect coquis to be important in mongoose and rat diets. If coquis interact with

94 rats through apparent competition, we predict that mongoose populations will be higher and rat

95 populations will be lower in areas with coquis. We would also expect mongooses to have rats in

96 their diets. If coquis compete with rats for resources, we predict that rat abundance will be lower

97 in areas with coquis, and that rats and coquis will consume similar prey. Finally, if coquis

98 increase bird nest predation through either increases in mongoose or rat abundances, we expect

99 nest predation rates will be higher in areas with coquis than in areas without coquis.

100 To address these hypotheses and predictions, we determined the relationship among

101 coquis, mongooses, and rats to determine if coquis or the other invasive mammal were important

102 predictors of mongoose and rat abundance. To determine whether predation or competition

103 might be occurring between coquis, mongooses, and rats, we investigated mongoose and rat

104 stomach contents in the presence and absence of coquis, and direct scavenging on coquis.

105 Finally, to determine if coquis indirectly influenced bird nest predation, we investigated nest

106 predation rates in the presence and absence of coquis. 


\section{Methods}

109 Study sites

110 We conducted research at 12 sites on the island of Hawaii in areas with coqui invasion

111 fronts (Fig. 1). Coqui invasion fronts are defined as the edge of established coqui populations, 112 and where habitat in close proximity differs only in the presence or absence of the frog. Eleven

113 of these sites were located near areas used in previous studies investigating the impacts of coquis 114 on invertebrates and birds (Choi and Beard 2012; Smith et al. 2018). We added one site (site 115 Upper Stainback [US]; Fig. 1) and adjusted the location of the plots at four sites (sites Eden Rock 116 [ER] Kalopa [KP] Stainback [SB], and Volcano [VC]) from the locations used in Smith et al. 117 (2018) because the invasion front had moved since that study. These were the only known 118 locations on the island where there was sufficient area on either side of the invasion front to 119 conduct our research and where habitat had been determined previously to be similar on both 120 sides of the front (Choi and Beard 2012; Smith et al. 2018).

121 At each site, we set up two circular 2.01-ha plots (diameter: $160 \mathrm{~m}$ ), one on either side of 122 the invasion front, in which all measurements were made. Plots on either side of the front had a 123 mean distance of $1163 \mathrm{~m}$ (range: 297 to $2954 \mathrm{~m}$ ) between them, with the fronts roughly half way 124 between them. We wanted plots to be close enough to each other to maintain similar habitats, but 125 not so close that many individual mammals would be moving between them. While we cannot 126 assume complete independence between either side of the invasion front, we feel that it is safe to 127 assume that any movement of small mammals across the front occurred at random and did not 128 affect our ability to address our objectives (as in Smith et al. 2018). Because coqui populations 129 are often near roads (Olson et al. 2012), we placed both coqui and non-coqui plots the same 130 distance $(>50 \mathrm{~m}$ ) from roads, trails, buildings, agricultural fields, or other such habitat edges to 
131 avoid biasing small mammal observations. We confirmed coqui presence and absence on both 132 sides of the front by listening for 20 minutes during peak calling hours, 1900 to $0200 \mathrm{~h}$ 133 (Woolbright 1985), for the male's two-note mating call on at least three separate nights no more 134 than two months prior to sampling.

135 Previous studies in 11 of 12 of our sites found no measurable differences in habitat on 136 either side of the front (Choi and Beard 2012; Smith et al. 2018). Because this study was initiated 137 two years after the previous study (Smith et al. 2018) and the location of some sites were 138 adjusted, we tested for differences in habitat across fronts by measuring the following variables 139 in both plots at each site: elevation, canopy cover, vegetated ground cover, percent understory 140 density, and dominant canopy and dominant understory species (explained in detail in 141 Supplemental Material A). For each variable, we tested for differences in habitat across paired 142 plots using a one-way analysis of variance (ANOVA) with coqui presence/absence as the fixed 143 effect, and site as a random block effect. We detected no differences in these variables across 144 coqui and non-coqui plots (Supplemental material A). Of note, a previous study more thoroughly 145 tested, both statistically and in terms of the field variables collected, habitat difference between 146 these sites and dropped 5 of 20 sites from their analysis that were sufficiently different in terms 147 of habitat variables (Choi 2011). We used 11 of the sites remaining after that analysis. In 148 summary, these 11 sites had no measurable habitat differences across the front, in either of the 149 previous studies or this study.

151 Mongoose and rat abundance

152 To test whether the abundance of non-native mammals is related to coqui frog presence 153 or absence, we estimated mongoose and rat abundances in coqui and non-coqui plots at each of 
154 the 12 sites with trapping webs. We conducted mongoose and rat trapping from December 2015 155 to July 2016. Each trapping web consisted of 16, 80-m transects radiating from a central point 156 and covering 2.01 ha, with one web on either side of the invasion front. We set eight live cage 157 traps (Tomahawk Live Trap Company, Tomahawk, WI), one every $10 \mathrm{~m}$, along each alternating 158 transect. On the remaining transects, we placed eight snap traps (Victor rat traps, Woodstream 159 Corporation, Lititz, PA), one every $10 \mathrm{~m}$. We baited live traps with uncooked cocktail links 160 soaked in fish oil, suspended by a hook in the back of each trap, while snap traps were baited 161 with chunks of coconut. We checked each trap twice daily, once at dawn and again at dusk, for 162 seven days at each site. We identified trapped rats to species. We euthanized each individual 163 captured in a live trap via $\mathrm{CO}_{2}$ saturation. Mongoose and rat relative abundance indices were 164 defined as the number of individuals caught relative to the total number of trap nights (1 trap 165 night is equal to a trap set for one night) at each site or capture per unit effort (CPUE). We also 166 estimated rat and mongoose abundances using depletion analysis for all plots (Supplemental 167 Material B).

168 Coqui density, in addition to presence, may affect rat and mongoose abundances. Within 169 each invaded plot, we estimated coqui density using the line-transect distance-sampling survey 170 methods (Buckland et al. 2001) used by and described in Choi and Beard (2012), Kalnicky et al. 171 (2013), and Smith et al. (2018). In summary, we placed $30 \mathrm{~m}$ x $30 \mathrm{~m}$ plots in the center of the 1722.01 ha plots on the coqui side of the invasion front. Then, for one night at each site, we walked 173 down the center of each of six 5-m wide, 30-m long transects for 30 minutes (for a total of 180 174 minutes per plot) and recorded all frogs at any height seen or heard and their distance from the 175 center of the transect. Coqui densities were estimated using the distance-sampling functions in 176 the package "unmarked" (Fiske and Chandler 2011) in R (R Core Team 2016). All distance 
177 sampling data was modeled with null models for density using either half-normal, hazard, or 178 exponential distributions. Akaike Information Criterion (AIC) values for the most supported 179 detection distributions and $p$-values for Freeman-Tukey goodness of fit tests are provided (see 180 Supplemental material B).

181 To determine the effect of coqui presence and absence on the abundance indices of small 182 mammals, we used generalized linear mixed models (GLMM) in R (R Core Team 2016) using 183 the "glmer" function within the "lme4" package (Bates et al. 2015). Each mammal species (e.g., 184 mongoose, black rat, and Pacific rat) was modeled separately, assuming a Poisson distribution, 185 with number of captures at each plot as the dependent variable offset by log(trap nights) to allow 186 interpretation of estimates as CPUE. We tested for differences in abundance using coqui 187 presence/absence as the fixed effect, and site as a random block effect to account for the non188 independence between paired trap webs at each site. We also tested correlation of coqui density 189 estimates from coqui plots with abundance indices of rats and mongooses using Pearson's 190 correlation coefficient to determine the strength and significance of the relationships between 191 each species and coqui frogs using the "cor.test" function in R.

192 The predation and resource competition hypotheses only include the possibility of coquis 193 influencing invasive mammals. The alternative hypothesis regarding apparent competition 194 includes interactions among mammalian species. We tested this competing hypothesis by 195 running a model similar to that previously described substituting plot type (i.e., coqui 196 presence/absence) as the independent variable with rat species CPUE in the mongoose model, 197 mongoose CPUE in both black rat and Pacific rat models, Pacific rat CPUE in black rat model, 198 and vice versa for the Pacific rat model. We identified top models as those with the lowest AIC 
199 values using a $\triangle \mathrm{AIC}<2$ criteria. We also did a Pearson's correlation test between each of these

200 species abundances.

202 Rat and mongoose diet

203 We removed the stomachs of the euthanized specimens collected from our trapping 204 efforts to analyze mongoose and rat diets. We froze stomachs at $-20^{\circ} \mathrm{C}$ for later analysis in the 205 laboratory. After thawing, we swirled the contents of each sample for 5 min in water and a mild 206 detergent to dissolve any stomach fluids and oils, poured the contents through a $0.4 \mathrm{~mm}$ sieved 207 and preserved them in 95\% ethanol (Sugihara 1997). For each sample, we performed a thorough 208 search of the stomach contents for coqui remains, such as skin and bones, under a dissecting 209 scope. We then used a grid of $5 \mathrm{~mm}$ x $5 \mathrm{~mm}$ squares laid under a Petri dish to inspect each 210 sample with a dissecting scope 10-20x magnification. For stomach samples too large for Petri 211 dishes, we gently stirred these samples for 30 seconds and took sub-samples by pouring $50 \%$ of 212 the contents onto a grid. We recorded the food type found within each grid-square (i.e. 40 evenly 213 spaces grid-boxes). We categorized food into seven major types: plant, arthropod, reptile, 214 amphibian, bird, rodent and other (as in Shiels et al. 2013). We were able to distinguish between 215 reptile and amphibian remains through skin fragments and portions of head, claws, tails, and 216 other body parts present in the samples. We sub-categorized plant food types as fruit, seed, and 217 other plant material (flowers, vegetative material, and unknown), and arthropods as Coleoptera, 218 Diptera, Lepidoptera, and other arthropod material (other included Hymenoptera, Chilopoda, 219 Odonata, Orthoptera, Gastropoda, Arachnida, and unknown arthropod material). Stomach 220 contents placed in the "other" category were items that we could not identify. We removed 
221 parasitic roundworms from the analysis and excluded empty stomachs and samples that 222 contained a volume greater than $50 \%$ of roundworms or trap bait from the study. 223 We determined the frequency of each food type by noting the occurrence of that food 224 type in each sample (Shiels et al. 2013). We calculated relative abundance in each sample by 225 dividing the number of squares with a certain food type by the total number of squares covered 226 by the contents of each stomach (Shiels et al. 2013). We compared relative abundances or 227 percent of food types among all species, and tested for differences in the diets of each species 228 individually between coqui plots and non-coqui plots, using the non-parametric analysis Multi229 Response Permutation Procedure (MRPP), an analysis for testing for difference between two or 230 more groups (Mielke et al. 1981) in the "vegan" package (Oksanen et al. 2017) for R. We tested 231 for differences in diet composition among the three species using all plots. We then assessed 232 differences in diet composition between coqui and non-coqui plots for each predator species 233 individually. For all statistical tests in this study, we used $\alpha<0.05$ as significant, except for diet 234 analyses of invertebrates, where we also discuss results with $\alpha<0.10$ because of the high degree 235 of spatial and temporal variability observed with invertebrate data (sensu Holmes and Schultz 236 1988; Tuttle et al. 2009).

238 Coqui scavengers

239 To determine scavenging on coquis, from December 2015 to July 2016, the week before 240 we began nest predation tests at each site (see below), we placed 25 dead coquis in the 2.01-ha 241 plot on the coqui invaded side of the front. We collected these coquis from near each coqui242 invaded plot, but not within plots, and euthanized them. Each dead coqui was placed on the 243 ground or within $50 \mathrm{~cm}$ of the ground on varying substrates to simulate where frogs might be if 
244 they had died naturally. Frogs were placed randomly but at least $15 \mathrm{~m}$ apart. We made

245 observations of scavenging events with a motion-activated camera (Reconyx HyperFire models,

246 Reconyx Inc., WI, USA) on each carcass positioned 1 to $2 \mathrm{~m}$ from the dead coqui. Cameras

247 remained in the field for seven days. We recorded each visitation of all carcasses regardless of

248 species. We summarized the camera trap data to determine which species were the most frequent

249 scavengers of coquis. Species were differentiated based on known distinguishing characteristics

250 except for black rats and Pacific rats, which were pooled because they could not be reliably

251 distinguished. Individuals were assumed the same until they left the field of view. We could not

252 reliably distinguish individuals from one another across multiple scavenging events.

253 From May to July 2017, we returned to the five sites with the greatest number of visits

254 from scavengers (sites ER, HM, KP, MB, and WP; Fig. 1) to validate our method by

255 characterizing differences in observations between cameras baited with a coqui carcass

256 (treatment cameras) and cameras without a coqui as bait (control cameras). Following methods

257 from the previous field season, we placed 21 to 24 cameras in each coqui plot, balanced between

258 treatment and control. Because there were no coquis to be scavenged from the control cameras,

259 the data collected here were counts of visits to the field of view of each camera that triggered the

260 motion sensor. In addition, to capture invertebrate scavengers that would not activate the

261 cameras' motion sensors, we placed all frog carcasses on pressure-sensitive external lever

262 triggers that would activate cameras when a frog was removed. These were not used in the

263 previous field season but were thought potentially to be important based on results from

264 Abernethy et al. (2016). To test for differences in the number of visits to cameras with frogs and

265 control cameras, we used a GLMM with camera set type (coqui or control) as a fixed effect, site 
266 as a random effect, and the sum of visits to each camera set type for each site as the dependent

267 variable, assuming a Poisson distribution.

269 Nest predation

270 To test whether nests are visited by predators at higher rates in sites where coqui occur, 271 we monitored artificial nests with quail eggs in our plots (VanderWerf 2001). From December 2722015 to July 2016, the week before we began trapping at each site, we placed 25 artificial nests 273 in each of the 2.01-ha plots on both sides of the invasion front. Artificial nests were $10-\mathrm{cm}$ in 274 diameter, 3-cm deep, and constructed of weaved plant fibers. We placed nests randomly but at 275 least $15 \mathrm{~m}$ apart, $0.25 \mathrm{~m}$ to $2.0 \mathrm{~m}$ from the ground, and on a variety of plant substrates, 276 depending on the site, including crooks of branches, along horizontal branches, and within 277 bundles of ferns. Within each nest, we placed one locally farmed quail egg. Between 1 and $2 \mathrm{~m}$ 278 from each nest, we placed a motion-activated camera to identify which species depredated the 279 egg. Each nest was monitored for seven nights. Nests were counted as depredated if the eggs 280 were gone, removed from nest, or had received damage in any way from predators during the 281 seven nights. We reused nests among sites after waiting at least seven days for odors that may 282 have attracted or repelled predators to the nest to dissipate between each use (VanderWerf 2001). 283 We tested the effect of coqui presence on the rate that the nests were depredated and the 284 number of predation events by rats and mongooses individually. To test coqui effect on 285 depredation rates, we ran a GLMM in R using the "glmer" function within the "Ime4" package. 286 Using binomial distributions, we tested for differences in nest depredation using coqui 287 presence/absence as the fixed effect and site as a random block effect. We tested the effect of 288 coquis on the number of predation events by each predator with a similar GLMM, but assuming 
289 a Poisson distribution of the count data and number of predation events by each predator as the 290 dependent variable.

292 Results

293 Mongoose and rat abundance

294 Mongooses were caught exclusively in live traps, while rats were caught in both trap 295 types, but most frequently ( $86 \%$ of the time) in snap traps. Because mongoose were only caught 296 in Tomahawk live traps, mongoose trapping effort was 448 trap nights per plot (7 days of 297 trapping with 64 live traps). Because rats were caught in both types of traps, we had 896 trap 298 nights per plot (seven days of trapping with 128 traps). There were no trap nights or days in 299 which two individuals were caught in the same trap. We compared CPUE (captures per 100 trap 300 nights) with results from depletion modeling, but because results were not qualitatively different 301 and showed the same patterns with coquis, we only present capture data per 100 trap-nights in 302 the text for comparability with other studies (Puan et al. 2011; Sugihara 1997). Depletion 303 estimate results are reported in Supplemental material B.

304 In total, 705 small mammals were collected across all sites: 194 mongooses, 262 black 305 rats, and 209 Pacific rats. Seven Norway rats (R. norvegicus) were trapped at one site (ER), and 30633 house mice (Mus musculus) were trapped at five sites and but not further analyzed due to low 307 sample size and zero counts at many sites.

308 Among all the models run, coqui presence or absence was the top predictor of the 309 relative abundance of mongoose and of Pacific rats. Pacific rat CPUE was the top predictor in 310 the black rat model (Table 1). The mean predicted relative abundance estimates from the 311 mongoose model were significantly greater for plots with coqui (2.13/100 trap nights) than 
312 without coqui (1.64/100 trap nights; $p<0.001$; Fig. 2$)$ and showed a $30 \%$ greater abundance of

313 mongooses. Mean predicted relative abundance for Pacific rats was significantly less for plots

314 with coqui than without (1.75 vs. $2.10 / 100$ trap nights; $p=0.012$; Fig. 2 ), showing a $17 \%$

315 difference. Mean predicted black rat abundances were negatively correlated with Pacific rat

316 abundance $(\mathrm{df}=11, \mathrm{z}=-2.186, p=0.028)$ but were also lower in sites with coqui (1.92 vs.

$3172.21 / 100$ trap nights), though this effect was not significant ( $p=0.262$; Fig. 2).

318 While the directions of the estimated relationships were consistent with the presence or

319 absence results, mongoose and rat abundance indices were not significantly correlated with coqui 320 density estimates (mongooses, $\mathrm{r}=0.05, p=0.87$; black rats, $\mathrm{r}=-0.25, p=0.43$; Pacific rats, $\mathrm{r}=-$ $3210.25, p=0.42 ;$ Supplemental material B).

323 Rat and mongoose diet $324 \quad$ Trapping efforts yielded 194 mongoose stomach samples, of which 72 were empty and 32516 contained $>50 \%$ by volume intestinal parasites or bait. There was a total of 262 black rat 326 stomachs, of which 63 were empty and 33 were $>50 \%$ parasites or bait. Finally, out of 209 327 Pacific rat stomachs, 54 were empty and 14 contained $>50 \%$ parasites or bait. In total, there were 328413 stomachs (106 mongoose, 166 black rat, and 141 Pacific rat) included in analyses.

329 Coqui frogs were found only in stomach contents from mammals trapped in coqui plots. 330 The frequency of stomachs from coqui plots $(n=216)$ containing coquis was low for all species: 331 five out of $69(7.2 \%)$ mongoose stomachs, two out of $87(2.3 \%)$ black rat stomachs, and one out 332 of $60(1.7 \%)$ Pacific rat stomachs. The abundance of coqui frogs relative to all stomach contents 333 of individuals trapped in coqui plots was also low for all species: $3.7 \%$ of mongoose diet, $0.1 \%$ 334 of black rat diet, and $1.3 \%$ of Pacific rat diet on average. 
Relative abundance of each food type was calculated from stomachs of 106 mongooses,

336141 Pacific rats, and 166 black rats regardless of the plot type in which they were caught.

337 Mongoose diets contained all recorded food types, and the composition of all food types differed

338 significantly from those of black rats and Pacific rats $(p=0.001$; Fig. 3$)$. When we compared

339 black rat and Pacific rat diets, we found a higher percent of plant material in black rat stomachs

$340(p=0.005)$, and a higher percent of arthropods in Pacific rat stomachs $(p=0.002 ;$ Fig. 3$)$. The

341 remaining food type categories had low percentages and were not compared.

342 For mongoose, only the mean percent of fruit differed between coqui and non-coqui plots

$343(p=0.045)$, with a greater percent of fruit found in stomachs in coqui plots. Similarly, for black

344 rats, there was a greater percent of fruit $(p=0.003)$ and other plant material $(p=0.027)$ in

345 stomachs in coqui plots. Results also suggest a greater percent of invertebrates in rat stomachs in 346 non-coqui than coqui plots (black rat: $p=0.099$ ), most notably more caterpillars in Pacific rat

347 diets $(p=0.068 ;$ Table 2$)$.

349 Coqui scavengers

350 Of the 384 dead frogs placed in study plots, $267(70 \%)$ were removed. Of those

351 scavenging events, we could determine the scavenger in 228 cases $(85.4 \%)$. In the remaining

352 cases, the camera failed to capture an image of the scavenger. Average time to removal was 56

353 hours $(\mathrm{SD}=36.8$ hours). We observed six species scavenging coquis. Mongooses were the most

354 frequently observed scavengers ( $60.5 \%$ of 228 confirmed events), followed by rats $(34.2 \%)$, pigs

355 (Sus scrofa, 3.1\%), ants (species unidentified, 1.3\%), one domestic cat (Felis catus, 0.4\%) and 356 one northern cardinal (Cardinalis cardinalis, 0.4\%). In 2017, there were more images recorded 
357 of potential scavengers at coqui carcass-baited cameras $(84.2 \%$ recorded images, $n=57)$ than at 358 unbaited control cameras (50\% recorded images, $\mathrm{n}=58)(\mathrm{z}=2.145, p=0.03)$.

360 Nest predation

361 We observed 564 artificial nests for nest predation $(n=283$ in coqui plots and 281 in 362 non-coqui plots, Supplemental material C). In total, $40.6 \%$ of the nests were depredated; there 363 was no difference in the percentage of nests depredated in coqui versus non-coqui plots. On 364 average $56.7 \%$ of nests were confirmed to be depredated by rats, $28.9 \%$ by mongooses, and 14.4 $365 \%$ were depredated by unidentified predators (cameras failed to capture an image). Neither of the 366 nest predation rates for rats nor mongooses differed between coqui or non-coqui plots $(z=0.754$, $367 p=0.45$ and $\mathrm{z}=0.858, p=0.39$, respectively).

369 Discussion

370 We set out to address the hypothesis originally proposed by Kraus et al. (1999) that 371 mongoose and rats depredate coqui frogs, which in turn increases mongoose and rat abundance, 372 and subsequently increases bird nest predation. In support of this hypothesis, we found $30 \%$ 373 more mongoose where coquis were present on the island of Hawaii and mongoose were also the 374 most important scavengers of coqui. In contrast, we found $17 \%$ fewer Pacific rats where coquis 375 were present, which suggests they are not important predators of coqui, and provides support for 376 both the apparent competition or resource competition hypotheses for coquis and rats. We found 377 more support for the resource competition hypothesis than the apparent competition hypothesis, 378 primarily because coquis were in the top model for Pacific rat abundance, were a better 379 explanatory variable than mongoose, and because rat diets shifted towards more fruit and less 
380 invertebrates in the presence of coquis. Perhaps because mongoose increased and rats decreased

381 in abundance in the presence of coquis, we found no support for the hypothesis that coquis

382 indirectly increase bird-nest predation rates.

383 Where coqui frogs occur, we found, on average, 30\% more mongooses than in areas

384 without frogs. Other studies have shown the importance of interactions between frogs and

385 mongooses by showing that frog species decline where mongooses invade (Barbour 1930; Barun

386 et al. 2010; Gorman 1975; Watari et al. 2008). We are not aware of other studies showing that

387 frogs increase mongoose abundance, although we might expect this relationship more frequently

388 at the beginning of an invasion or at an invasion front (Simberloff and Gibbons 2004). In our

389 study, mongooses were the most common predators and scavengers of coquis. While direct

390 predation likely contributed to the increased abundance of mongooses we observed, the relative

391 abundance (4\%) and frequency (7\%) of coquis in the stomachs we investigated from coqui plots

392 seems low to explain the increase entirely.

393 Previous research in Hawaii has shown an individual mongoose can consume a high

394 number of coquis (remains of 15 frogs in one stomach) (Beard and Pitt 2006). We did not find

395 that to be the case in our study; rather we found at most four frogs in one mongoose stomach. We

396 offer several potential explanations for this pattern. First, perhaps mongoose consumed more

397 coquis than we observed, but they were digested quickly. Second, mongoose may only

398 opportunistically consume coquis, such as at particular times of year or life stages (Barun et al.

399 2010; Yamada 2002) that were not captured in our sampling. Finally, our results could reflect

400 that coquis indirectly increase mongooses, such as by altering available forage (e.g. by increasing

401 non-native fruit as discussed below; Sin et al. 2008). 
In general, we found both rat species had lower indices of relative abundance in coqui

403 than in non-coqui plots, but only Pacific rats were significantly lower, on average by $17 \%$. A 404 possible explanation for this pattern is apparent competition between coquis and rats, or more 405 specifically, that greater mongoose abundance in coqui plots resulted in greater mongoose 406 predation on rats or rat avoidance of coqui plots (Barnum 1930; Barun et al. 2011; Doty 1945; 407 Pimentel 1955; Seaman and Randall 1962; Walker 1945). We expected greater potential for 408 apparent competition with the less-arboreal Pacific rats because they are more likely to interact 409 with mongooses (Pimentel 1955; Shiels 2010; Walker 1945). Our results support this because 410 Pacific rat abundances were lower in coqui plots. Further, we found that rodents made up $27 \%$ of 411 mongoose diets. However, the top models for predicting either rat species' relative abundance 412 did not include mongoose. Therefore, while apparent competition may play a role in reducing 413 rats where coquis are present, it is likely not the only factor.

414 We expected that coquis may compete with less-arboreal Pacific rat, in particular, for 415 invertebrate prey. Coquis are, after all, insectivores, and most directly impact and reduce leaf 416 litter invertebrates (Beard 2007; Choi and Beard 2012). In support of the resource competition 417 hypothesis, coquis were in the top model and were a better explanatory variable of Pacific rat 418 abundance than mongooses. Further, Pacific rats consumed more arthropods than black rats in 419 our study, so we would expect to observe a greater reduction in Pacific than black rats if 420 competition for invertebrates was important. Finally, we found a greater relative abundance of 421 arthropods (in general or some type) in rat diets from non-coqui plots than coqui plots.

422 Therefore, competition for invertebrate resources appears to be another, at least partial, 423 explanation for the lower Pacific rat abundance in coqui plots. 
There seems to be a dietary shift for mongooses and rats across the coqui invasion front,

425 in which both mongooses and black rats, in particular, were consuming more fruit in areas with

426 frogs compared to areas without frogs. Previous research suggests that the growth rate of

427 strawberry guava, Psidium cattleianum, in particular, a dominant non-native plant in many of 428 these sites, is greater in areas with coqui frogs (Sin et al. 2008). We did not measure the number 429 of fruits produced per plot, but future research should determine if fruit availability differs 430 between coqui and non-coqui plots. Our results are consistent with greater frugivory by 431 mongooses and rats in areas invaded by coqui than in areas not invaded.

432 Our study shows that other invasive species, most frequently mongooses, scavenge on 433 coquis. Abernethy et al. (2016) found that vertebrates scavenge $22 \%$ of the frogs placed in the 434 field, while we found vertebrates scavenge them $84 \%$ of the time. This difference may be due to 435 the fact that coquis were not established in the native-dominated sites used by Abernethy et al. 436 (2016) and the fauna present were not conditioned to search for such small-bodied amphibians. 437 We also observed a much lower rate of frogs removed by invertebrates. Abernethy et al. (2016) 438 observed $78 \%$ of frog carcasses removed by invertebrates. The only invertebrates we observed 439 scavenging frogs were ants, $6.3 \%$ of the time (invertebrates were only evaluated in 2017 field 440 season, but $86 \%$ of our predation events were accounted for in the 2016 field season). Our results 441 suggest that in non-native dominated sites with established coqui populations, vertebrates are 442 more important scavengers than invertebrates, and that they consume a high percentage of dead 443 coqui frogs if they are readily available.

Even though we found differences in the abundance of mongooses and rats where coquis occur, we were unable to detect any difference in the percent of depredated artificial nests for mongoose or rats in coqui invaded and uninvaded areas. We observed a greater number of rats 
447 (56.7\%) depredating nests compared to mongooses (28.9\%), which was expected because we 448 placed nests $0.25-2 \mathrm{~m}$ off the ground, and black rats, in particular, are more arboreal than 449 mongooses (Shiels 2010). However, of note, we frequently observed mongooses climbing to 450 remove eggs from relatively high nests; $64 \%$ of the nests that mongooses depredated were 451 between $0.75 \mathrm{~m}$ and $1.75 \mathrm{~m}$ (Supplemental material C). Studies have found that rat control can 452 increase nest success for native birds; we can infer that areas with less rats would have lower 453 nest predation (VanderWerf 2001; VanderWerf and Smith 2002). However, because coquis were 454 associated with increased mongoose abundance, decreased Pacific rat abundance, and no 455 difference in black rat abundance, we might expect a similar risk of nest depredation in both 456 coqui invaded and uninvaded areas.

457 We were simultaneously studying the effects of coquis on predators with differing life 458 histories. Our methods may have been adequate to capture the data we wanted for one species 459 while failing to do so for another. For example, the size of our plots remained constant despite 460 the difference in home ranges between mongooses and rats (Lindsey et al. 1999; Pitt et al. 2015). 461 A study on the effects of coquis on mongoose maybe should accommodate the large home 462 ranges (8.6 to $70.2 \mathrm{ha}$ ) of mongooses (Pitt et al. 2015). Also, most empirical evidence suggests 463 that mongooses are a larger threat to ground foraging and nesting birds (Hoshide et al. 1990; 464 Morley and Winder 2013) while rats can depredate nests higher in the canopy (Shiels 2010; 465 VanderWerf 2001; VanderWerf and Smith 2002). Future studies focused solely on mongooses or 466 rats may capture more robust data on the target species.

467 Our results suggest that either: 1) coquis are either directly or indirectly influencing the 468 abundance and dietary behavior of mongooses and rats, or 2) mongooses and rats are responding 469 to some other factor, independent of coquis, that varies between coqui and non-coqui plots. The 
470 similarities in vegetation structure across the invasion fronts as assessed by the current and past

471 studies suggests that vegetation structure and composition did not drive the differences we found 472 in mammal abundance and diets across the fronts (Choi and Beard 2012; Smith et al. 2018).

473 While we cannot rule out that some other factor contributed to the differences we found, we 474 think our study design is adequate to test relationships between coquis and mammals, and to 475 develop hypotheses that can be tested using more targeted experimental designs.

476 In conclusion, the results of our research partially support the hypothesis proposed by 477 Kraus et al. (1999) that coquis may increase populations of invasive small mammals in Hawaii. 478 The presence of coquis is associated with greater mongoose abundance, probably through direct 479 consumption of a novel prey. The association of increased mongoose abundances in areas with 480 coqui frogs should concern managers interested in conserving or restoring birds that mongooses 481 negatively affect. On the other hand, rat abundances seem to be lower in coqui-invaded plots, 482 possibly through both competition for resources and apparent competition. With the ever483 growing likelihood of future introductions of invasive species to Hawaii, coquis could facilitate 484 the successful establishment of other invasive predators. We recommend that managers continue 485 to monitor and prevent coqui movement across the island of Hawaii and to other locations, such 486 as Kauai and Oahu, which presently have no coquis.

488 Acknowledgements

489 We thank the USDA APHIS NWRC and the USU Ecology Center for funding; the NWRC Hilo 490 field station and technicians, A. Grant, J.J. Cieslewics, and J. Gardner for assistance; J. Young 491 for comments on earlier versions of this manuscript and S. Durham for statistical help. This 492 research was supported by the Utah Agricultural Experiment Station, Utah State University, and 
493 approved as journal paper number 9102. This research was conducted under access permits from

494 the Hawaii Division of Forestry and Wildlife, Natural Area Reserves System, State Parks

495 Department, and Injurious Wildlife Export Permit \#16-05 and was conducted in compliance with

496 USU's IACUC guidelines as protocols \#2519 and \#2753.

498 Author Contributions

499 Conceived and designed the research: Karen Beard and Aaron Shiels. Performed the research:

500 Shane Hill. Analyzed the data: Shane Hill and Shane Siers. Wrote the paper: Shane Hill and

501 Karen Beard. Helped revise the paper: all authors.

503 Compliance with ethical standards

504

505 Conflict of interest

506 The authors have declared that no competing interests exist.

508 References 
509 Abernethy E, Turner K, Beasley J, DeVault TL, Pitt WC, Rhodes OEJ (2016) Carcasses of

$510 \quad$ invasive species are predominantly utilized by invasive scavengers in an island

$511 \quad$ ecosystem Ecosphere 7:e01496 doi:10.1002/ecs2.1496

512 Atkinson IAE (1977) A reassessment of factors, particularly Rattus rattus L., that influenced the

513 decline of endemic forest birds in the Hawaiian Islands Pac Sci 31:109-133

514 Atkinson IAE (1985) The spread of commensal species of Rattus to oceanic islands and their

$515 \quad$ effects on island avifaunas ICPB Tech Publ 3:35-81

516 Baldwin P, Schwartz C, Schwartz E (1952) Life history and economic status of the mongoose in

$517 \quad$ Hawaii J Mammal 33:335-356 doi:10.2307/1375771

518 Barbour T (1930) Some faunistic changes in the Lesser Antilles Proc New Engl Xool Club

$519 \quad 11: 73-85$

520 Barnum C (1930) Rat control in Hawaii Hawaii Plant Rec 34:421-443

521 Barun A, Simberloff D, Budinski I (2010) Impact of the small Indian mongoose on native

522 amphibians and reptiles of the Adriatic islands, Croatia Anim Conserv 13:549-555

doi:10.1111/j.1469-1795.2010.00374.x

524 Barun A, Simberloff D, Tvrtković T, Pascal M (2011) Impact of the introduced small Indian

525 mongoose (Herpestes auropunctatus) on abundance and activity time of the introduced

526 ship rat (Rattus rattus) and the small mammal community on Adriatic islands, Croatia

$527 \quad$ NeoBiota 11:51-61 doi:10.1111/j.1469-1795.2010.00374.x

528 Beard KH (2007) Diet of the invasive frog, Eleutherodactylus coqui, in Hawaii Diet of the

529 invasive frog, Eleutherodactylus coqui, in Hawaii 2007:281-291

530 Beard KH, Pitt WC (2006) Potential predators of an invasive frog (Eleutherodactylus coqui) in

$531 \quad$ Hawaiian forests J Trop Ecol 22:345-347 doi:10.1017/S0266467406003154 
532 Beard KH, Price EA, Pitt WC (2009) Biology and impacts of Pacific Island invasive species. 5.

533 Eleutherodactylus coqui, the coqui frog (Anura: Leptodactylidae) Pac Sci 63:297-316

534 doi:10.2984/049.063.0301

535 Beckmann C, Shine R (2011) Toad's tongue for breakfast: Exploitation of a novel prey type, the 536 invasive cane toad, by scavenging raptors in tropical Australia Biol Invasions 13:1447$537 \quad 1455$ doi:10.1007/s10530-010-9903-8

538 Bernard RF, Mautz WJ (2016) Dietary overlap between the invasive coquí frog

(Eleutherodactylus coqui) and the Hawaiian hoary bat (Lasiurus cinereus semotus) on the

Island of Hawai'i Biol Invasions 18:3409-3418 doi:10.1007/s10530-016-1232-0

Buckland ST, Anderson DR, Burnham KP, Laake JL, Borchers DL, Thomas L (2001)

Introduction to distance sampling: Estimating abundance of biological populations. Oxford University Press, Oxford

544 Choi RT (2011) Invertebrate community changes along coqui invasion fronts in Hawai'i. M.S. $545 \quad$ Thesis, Utah State University

546 Choi RT, Beard KH (2012) Coqui frog invasions change invertebrate communities in Hawaii 547 Biol Invasions 14:938-948 doi:10.1007/s10530-011-0127-3

548 Davis M (2003) Biotic globalization: Does competition from introduced species threaten $549 \quad$ biodiversity? Bioscience 53:481-489 doi:10.1641/0006-

$550 \quad 3568(2003) 053[0481:$ bgdcfi $] 2.0 . c 0 ; 2$

551 Doty RE (1945) Rat control on Hawaiian sugar cane plantations. Hawaii Plant Rec 49:71-239

552 Fiske I, Chandler R (2011) Unmarked: An R package for fitting hierarchical models of wildlife $553 \quad$ occurrence and abundance. 
554 Gangoso L, Zar JAD, Scholz S, Palacios CJ, Hiraldo F (2006) Contradiction in conservation of 555 island ecosystems: plants, introduced herbivores and avian scavengers in the Canary 556 Islands Biodivers Conserv 15:2231-2248 doi:10.1007/s10531-004-7181-4 557 Gorman ML (1975) The diet of feral Herpestes auropunctatus (Carnivora: Viverridae) in the 558 Fijian Islands J Zool 175:273-278 doi:10.1111/j.1469-7998.1975.tb01401.x 559 Grosholz ED (2005) Recent biological invasion may hasten invasional meltdown by accelerating 560 historical introductions Recent biological invasion may hasten invasional meltdown by

Hadfield MG, Miller SE, Carwile AH (1993) The decimation of endemic Hawai'ian tree snails by alien predators Am Zoo 33:610-622 doi:10.1093/icb/33.6.610

Holmes RT, Schultz JC (1988) Food availability for forest birds: effects of prey distribution and abundance on bird foraging Can J Zool 66:720-728

Holt RD (1977) Predation, apparent competition, and the structure of prey communities Theor Popul Biol 12:197-229 doi:10.1016/0040-5809(77)90042-9

Hoshide H, Price A, Katahira L (1990) A progress report on Nene, Branta sandvicensis, in Hawaii Volcanoes National Park from 1974-89 Wildfowl 41:152-155

Kaiser B, Burnett K (2006) Economic impacts of E. coqui frogs in Hawaii Economic impacts of E. coqui frogs in Hawaii 8:1-11 doi:10.1504/IER.2006.053951

572 Kalnicky E, Brunson M, Beard K (2014) A social-ecological systems approach to non-native 573 species: Habituation and its effect on management of coqui frogs in Hawaii Biol Conserv $574 \quad$ 180:187-195 doi:10.1016/J.BIOCON.2014.09.044 
575 Kalnicky EA, Beard KH, Brunson MW (2013) Community-level response to habitat structure 576 manipulations: An experimental case study in a tropical ecosystem For Ecol Manage $577 \quad 307: 313-321$ doi:10.1016/J.FORECO.2013.07.015

578 Kraus F, Campbell EW (2002) Human-mediated escalation of a formerly eradicable problem: the 579 invasion of Caribbean frogs in the Hawaiian Islands Biol Invasions 4:327-332 580 doi:10.1023/A:1020909205908

581 Kraus F, Campbell EW, Allison A, Pratt T (1999) Eleutherodactylus frog introductions to $582 \quad$ Hawaii Herpetol Rev 30:21-25

583 Lindsey G, Mosher S, Fancy S, Smucker T (1999) Population structure and movements of

introduced rats in an Hawaiian rainforest. Pacific Conserv Biol 5:94-102 doi:10.1071/PC990094

Loope LL, Mueller-Dombois D (1989) Characteristics of invaded islands, with special reference to Hawaii. In: Drake JA, Mooney HA, di Castri F, Groves RH, Kruger FJ, Rejmanek M, Willaimson M (eds) Biological Invasions: A Global Perspective. John Wiley \& Sons, Chichester, pp 257-280

Mielke PW, Berry KJ, Brier GW (1981) Application of multi-response permutation procedures for examining seasonal changes in monthly mean sea-level pressure patterns Mon Weather Rev 109:120-126 doi:10.1175/1520-0493(1981)109<0120:AOMRPP>2.0.CO;2

O’Dowd DJ, Green PT, Lake PS (2003) Invasional ‘meltdown' on an oceanic island Ecol Lett 6:812-817 doi:10.1046/j.1461-0248.2003.00512.x

O’Loughlin LS, Green PT (2017) Secondary invasion: When invasion success is contingent on other invaders altering the properties of recipient ecosystems Ecol Evol 7:7628-7637 doi:10.1002/ece3.3315 
598 Oksanen J et al. (2017) vegan: Community Ecology Package.

599 Olson CA, Beard KH, Koons DN, Pitt WC (2012) Detection probabilities of two introduced

$600 \quad$ frogs in Hawaii: implications for assessing non-native species distributions Biol

$601 \quad$ Invasions 14:889-900 doi:10.1007/s10530-011-0125-5

602 Pimentel D (1955) Biology of the Indian mongoose in Puerto Rico J Mammal 36:62-68

603 doi: $10.2307 / 1375723$

604 Pitt W, Sugihara R, Berentsen A (2015) Effect of travel distance, home range, and bait on the

605 management of small Indian mongooses, Herpestes auropunctatus Biol Invasions

$606 \quad 17: 1743-1759$ doi:10.1007/s10530-014-0831-x

607 Puan CL, Goldizen AW, Zakaria M, Hafidzi MN, Baxter GS (2011) Relationships among rat

608 numbers, abundance of oil palm fruit and damage levels to fruit in an oil palm plantation

$609 \quad$ Integr Zool 6:130-139 doi:10.1111/j.1749-4877.2010.00231.x

610 R Core Team (2016) R: A language and environment for statistical computing.

611 Reed J, DesRochers D, VanderWerf E, Scott J (2012) Long-term persistence of Hawaii's

612 endangered avifauna through conservation-reliant management Bioscience 62:881-892

613 doi:10.1525/bio.2012.62.10.8

614 Rodriguez LF (2006) Can invasive species facilitate native species? Evidence of how, when, and

615 why these impacts occur Biol Invasions 8:927-939 doi:10.1007/s 10530-005-5103-3

616 Savidge JA (1987) Extinction of an island forest avifauna by an introduced snake Ecology

$617 \quad 68: 660-668$ doi:10.2307/1938471

618 Sax D, Gaines S, Brown J (2002) Species invasions exceed extinctions on islands worldwide: a

619 comparative study of plants and birds Am Nat 160:766-783 doi:10.1086/343877 
620 Seaman G, Randall J (1962) The mongoose as a predator in the Virgin Islands J Mammal $621 \quad 43: 544-546$ doi:10.2307/1376922

622 Shiels A (2010) Ecology and impacts of introduced rodents (Rattus spp. and Mus musculus) in

623 the Hawaiian islands. PhD Dissertation, University of Hawai'i

624 Shiels AB, Flores CA, Khamsing A, Krushelnycky PD, Mosher SM, Drake DR (2013) Dietary

625 niche differentiation among three species of invasive rodents (Rattus rattus, R. exulans,

626 Mus musculus) Biol Invasions 15:1037-1048 doi:10.1007/s10530-012-0348-0

627 Simberloff D, Gibbons L (2004) Now you see them, now you don't! - population crashes of 628 established introduced species Biol Invasions 6:161-172

629 Simberloff D, Von Holle B (1999) Positive interactions of nonindigenous species: invasional 630 meltdown? Biol Invasions 1:21-32 doi:10.1023/A:1010086329619

631 Sin H, Beard KH, Pitt WC (2008) An invasive frog, Eleutherodactylus coqui, increases new leaf 632 production and leaf litter decomposition rates through nutrient cycling in Hawaii Biol 633 Invasions 10:335-345 doi:10.1007/s10530-007-9133-X

634 Smith RL, Beard KH, Koons DN (2018) Invasive coqui frogs are associated with greater 635 abundances of non-native birds in Hawaii Condor 120:16-29 doi:10.1650/CONDOR-17$636 \quad 109.1$

637 Sugihara R (1997) Abundance and diets of rats in two native Hawaiian forests Pacific Sci $638 \quad 51: 189-198$

639 Tuttle NC, Beard KH, Pitt WC (2009) Invasive litter, not an invasive insectivore, determine 640 invertebrate communities in Hawaiian forests Biol Invasions 11:845-855

641 doi:10.1007/s10530-008-9298-y 
642 VanderWerf EA (2001) Rodent control decreases predation on artificial nests in O'ahu 'elepaio 643 habitat J Field Ornithol 72:448-457 doi:10.1648/0273-8570-72.3.448

644 VanderWerf EA, Smith DG (2002) Effects of alien rodent control on demography of the O'ahu 645 'Elepaio, an endangered Hawaiian forest bird Pacific Conserv Biol 8:73-81 646 doi:10.1071/PC020073

647 Vitousek P, Loope L, Stone C (1987) Introduced species in Hawaii: biological effects and 648 opportunities for ecological research Trends Ecol Evol 2:224-227 doi:10.1016/0169$649 \quad 5347(87) 90026-7$

650 Walker L (1945) The Hawaiian mongoose - friend or foe Nat Hist 54:396-400

651 Wallis A, Smith R, Beard K (2016) Temporal foraging patterns of non-native Coqui Frogs 652 (Eleutherodacytlus coqui) in Hawaii J Herpetol 50:582-588 doi:10.1670/15-170 653 Watari Y, Takatsuki S, Miyashita T (2008) Effects of exotic mongoose (Herpestes javanicus) on 654 the native fauna of Amami-Oshima Island, southern Japan, estimated by distribution 655 patterns along the historical gradient of mongoose invasion Biol Invasions 10:7-17 656 doi:10.1007/s10530-007-9100-6

657 Weller $\mathrm{S}$ et al. (2018) The effects of introduced ungulates on native and alien plant species in an 658 island ecosystem: Implications for change in a diverse mesic forest in the Hawaiian $659 \quad$ Islands For Ecol Manage 409:518-526 doi:10.1016/j.foreco.2017.11.023

660 Wilcove DS, Rothstein D, Dubow J, Phillips A, Losos E (1998) Quanitfying threats to imperiled $661 \quad$ species in the United States Bioscience 48:607-615 doi:10.2307/1313420 662 Woolbright LL (1985) Patterns of nocturnal movement and calling by the tropical frog $663 \quad$ Eleutherodactylus coqui Herpetologica 14:1-9 
664 Yamada F (2002) Impacts and control of introduced small Indian mongoose on Amami Island, 665 Japan IUCN SSC Invasive Species Spec Gr:389-392 


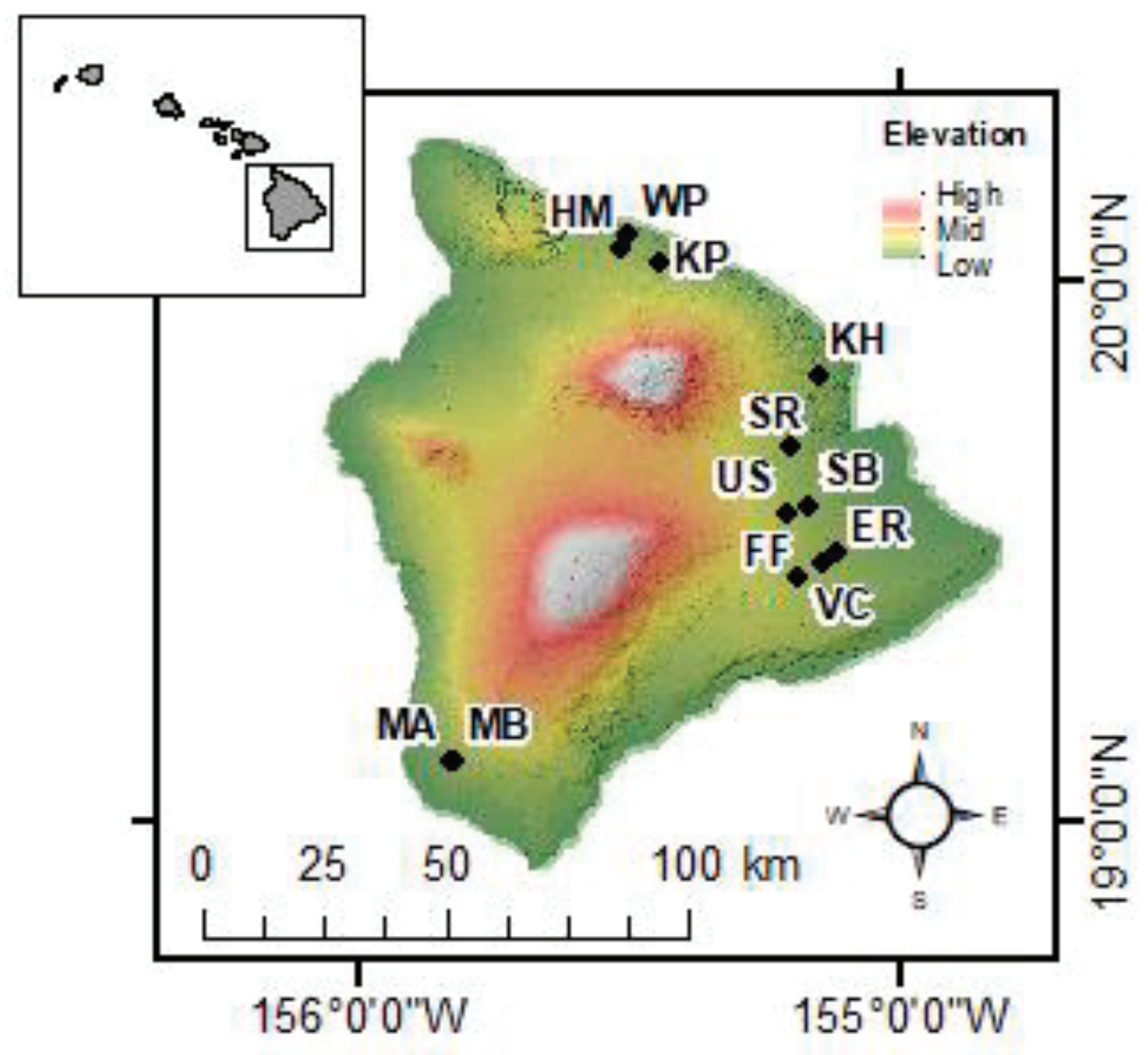

Fig 1. Twelve study sites on the island of Hawaii. Each site was comprised of paired study plots on either side of the coqui invasion front. Site abbreviations are Eden Roc (ER), Fern Forest (FF), Hamakua FR (HM), Kaupukuea Homestead (KH), Kalopa (KP), Manuka A (MA), Manuka B (MB), Stainback (SB), Upper Stainback (US), Saddle Road (SR), Volcano (VC), Waipio (WP). 


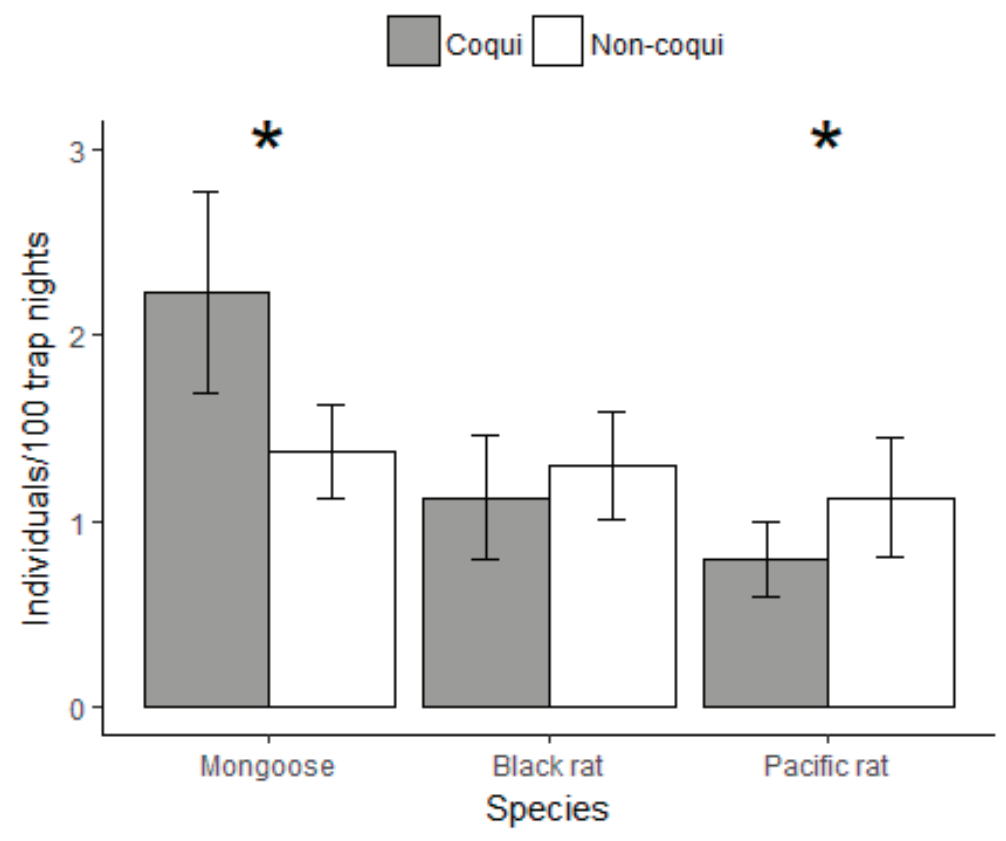

Fig. 2 Mean relative abundance indices (individuals/100 trap nights) with standard error bars for small mammals across 12 coqui and non-coqui sites. Significance based on GLMMs: * p $<0.05$ 


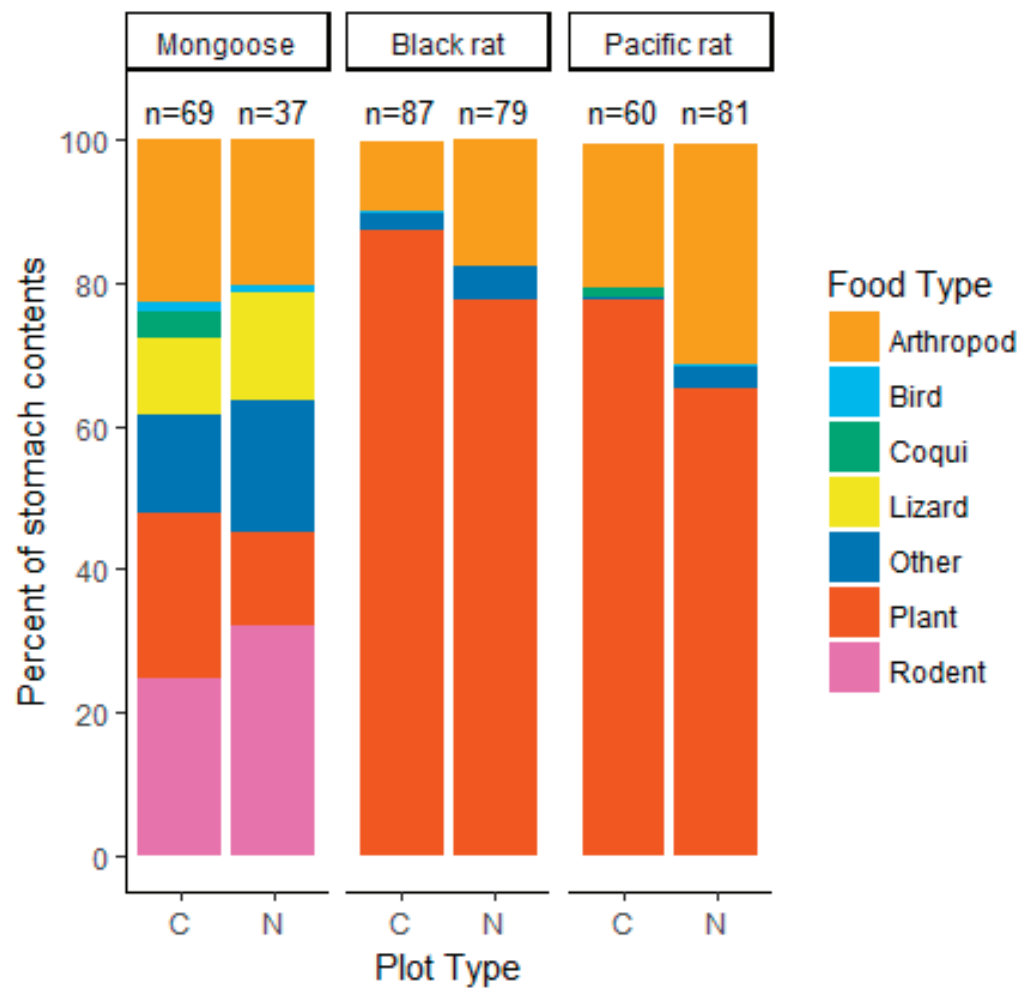

Fig. 3 Mean percent (\%) of major food types found in the stomachs of mongooses, black rats, and Pacific rats compared by plot type. Differences in percent of coqui in stomach contents between coqui plots and non-coqui plots were statistically non-significant for all three species. $\mathrm{C}=$ coqui plots $\mathrm{N}=$ non-coqui plots. ${ }^{*} \mathrm{n}$ does not include empty stomachs 


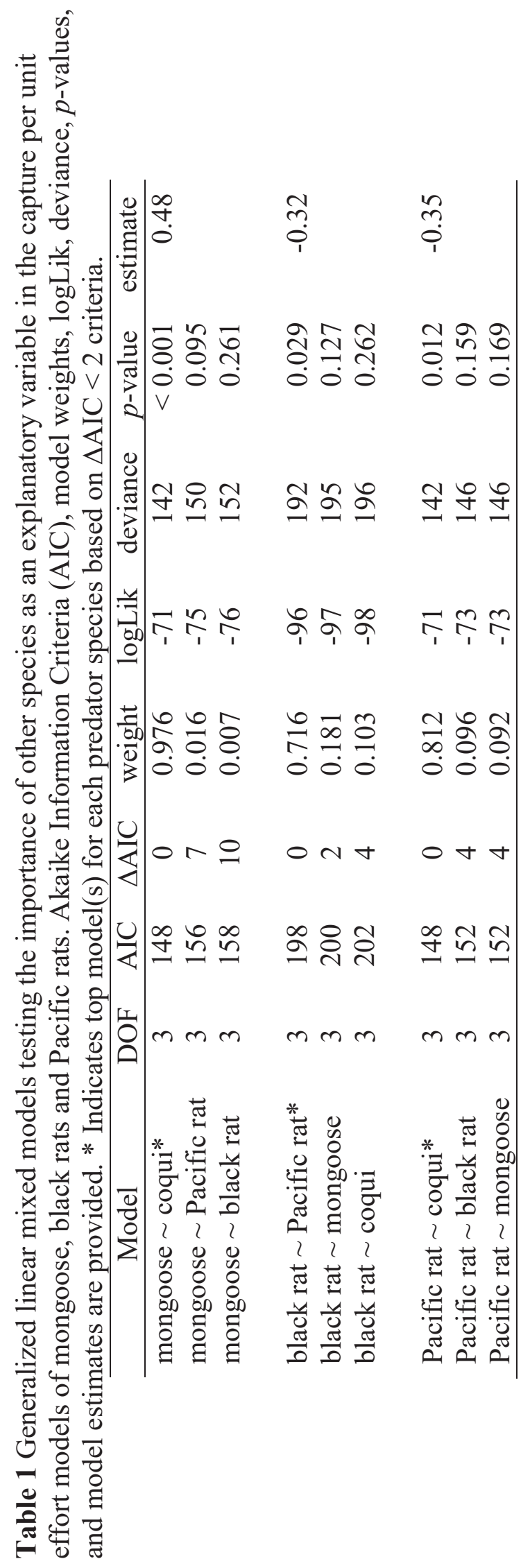




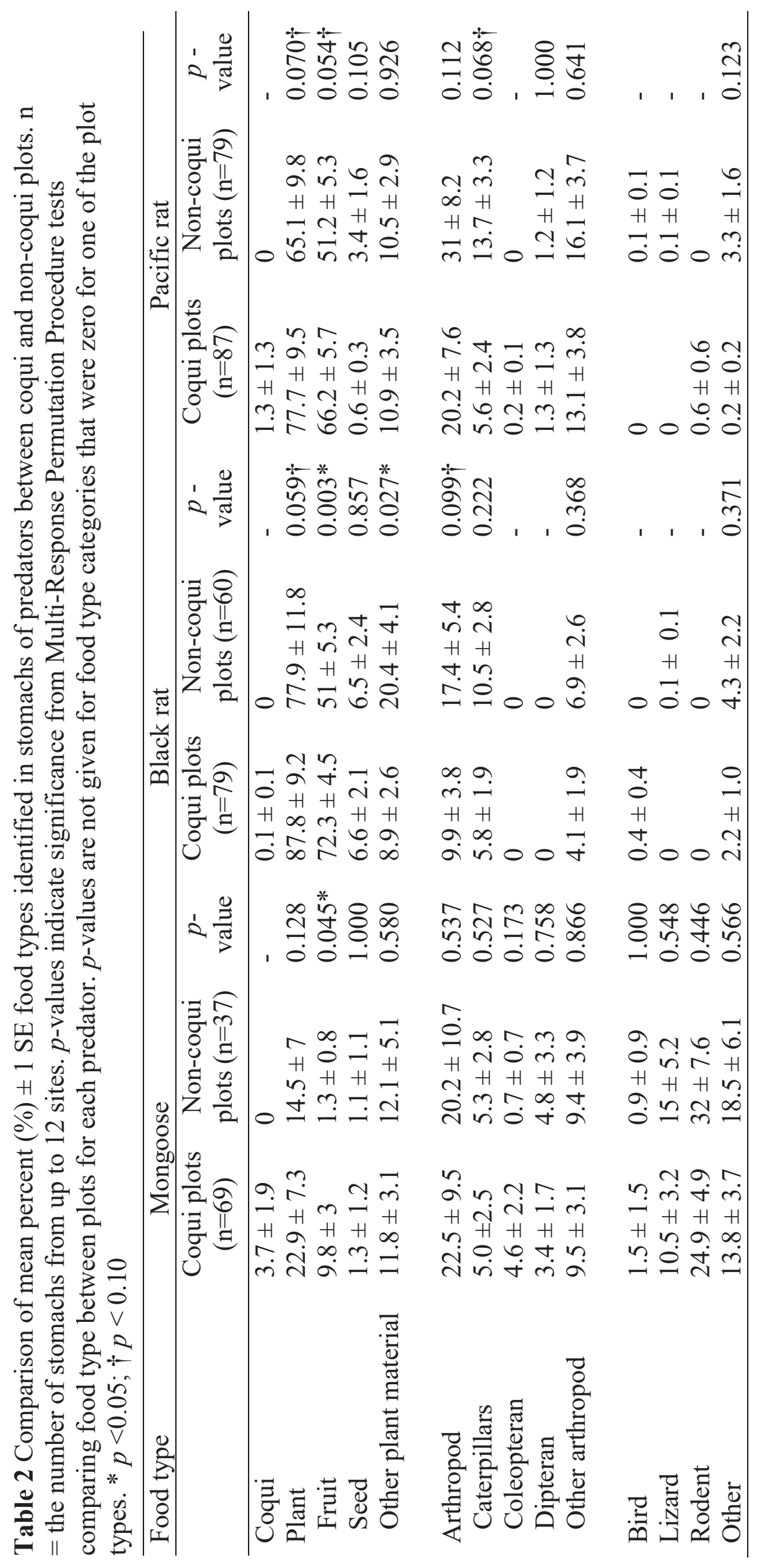

